\title{
Design of U-Shaped Slot Quad Band Patch Antenna
}

\section{Kuldip Kumar $^{1 *}$ - Arun S. Bahuguna ${ }^{1}$ Yogendra P. Pundir ${ }^{1} \cdot$ Don Biswas $^{2}$}

${ }^{1}$ Deptt. of ECE, HNB Garhwal University, Srinagar (Uttrakhand), India-246174.

${ }^{2}$ Deptt. of USIC, HNB Garhwal University, Srinagar (Uttrakhand), India-246174.

*Corresponding Author: kuldipkumarhnb@gmail.com

Received: 25.11.2021; Revised: 17.12.2021; Accepted: 27.12.2021

(C)Society for Himalayan Action Research and Development

\begin{abstract}
A four-band microstrip antenna with a U-shaped slot and two straight slots is proposed in this study. As the width of the dielectric substrate layer is extended, the frequency bands and antenna gain are observed to rise. In this current study, the suggested antenna is intended for using in wireless devices operating at frequencies between 5 $\mathrm{GHz}$ to $9 \mathrm{GHz}$.
\end{abstract}

Keywords: Patch Antenna, Multiband Microstrip antenna, Quad-Band Antenna, Slot Patch Antenna.

\section{Introduction}

A multi-band antenna for a multi-system handset is required due to the rapid advancement of wireless and mobile communication systems, as well as the growing demand for several applications in a single device via a single internal antenna (Rhazi et al 2018). The multiband microstrip antenna is commonly employed as an internal antenna in wireless mobile communication system applications (Bhattacharya and Garg 1985, Nataraj et al 2017, Chaurasia and Jain 2020, Kumar and Gangwar 2016) Dual or multiple bands of frequencies (Amal et al 2016, Rhazi et al 2019, Wang et al 2018, Cao et al 2015) can be obtained by employing the U-shaped slot in the antenna patch. Figure 1 depicts the proposed multi-band microstrip antenna geometry, which includes a U-shaped slot and two linear slots.
The main radiating patch, dielectric layer, ground plane, and feeding point comprise the microstrip antenna (IE3D 14, Zeland software Inc.).

The resonant frequency of the proposed antenna has been appropriately chosen to range between 5 and $9 \mathrm{GHz}$. As a result, the proposed antenna can operate at these frequencies. The maximum and minimum dimensions of the suggested antenna are calculated using the transmission line model (Bhattacharyya and Garg 1985, Garg et al 2001, Kumar and Ray 2003) for the frequency operation range of 5 $\mathrm{GHz}$ to $9 \mathrm{GHz}$. The dimensions obtained at the lowest frequency, $\mathrm{f}=5 \mathrm{GHz}$, are length, $\mathrm{L}=39$ $\mathrm{mm}$, and width, $\mathrm{W}=47 \mathrm{~mm}$. The dielectric constant of the Teflon dielectric layer is 2.25. Because the height of the dielectric substrate 
increases the bandwidth of a patch antenna, it is set to $3 \mathrm{~mm}$ in this design.

The multi-band frequency operation is provided by the U-shaped slot. The lengths S2, S3 and slot width $G$ of the $U$-shaped slot have been varied to find a higher resonance. The simulation is run for each variation in the geometry, and the return loss is checked at the desired frequencies. The best geometry of the resulting U-shaped slot is given as $\mathrm{S} 2=13 \mathrm{~mm}$, $\mathrm{S} 3=13.5 \mathrm{~mm}$, and slot gap $\mathrm{G}=0.8 \mathrm{~mm}$. Inserting two straight slots in a U-shaped slot antenna creates a long path for the current density distribution in the patch, resulting in two additional resonant frequencies. $\mathrm{S} 1=34 \mathrm{~mm}$ and slot gap $\mathrm{G}=0.8 \mathrm{~mm}$ are the dimensions of the two straight slots.

The simulation is conducted out using the IE3D software (IE3D 14, Zeland software Inc.) for various dimensions. We chose the dimensions that produced the highest resonance and multibands from these simulations. For the frequency range of $5 \mathrm{GHz}$ to $9 \mathrm{GHz}$, The best dimensions obtained using this procedure are length, $\mathrm{L}=39$ $\mathrm{mm}$, and width, $\mathrm{W}=47 \mathrm{~mm}$, which provide the maximum resonance and the maximum number of bands. Figure 2 shows four centre frequencies obtained with return loss less than $-10 \mathrm{~dB}: 5.82$ $\mathrm{GHz}, 6.86 \mathrm{GHz}, 7.85 \mathrm{GHz}$, and $8.10 \mathrm{GHz}$.

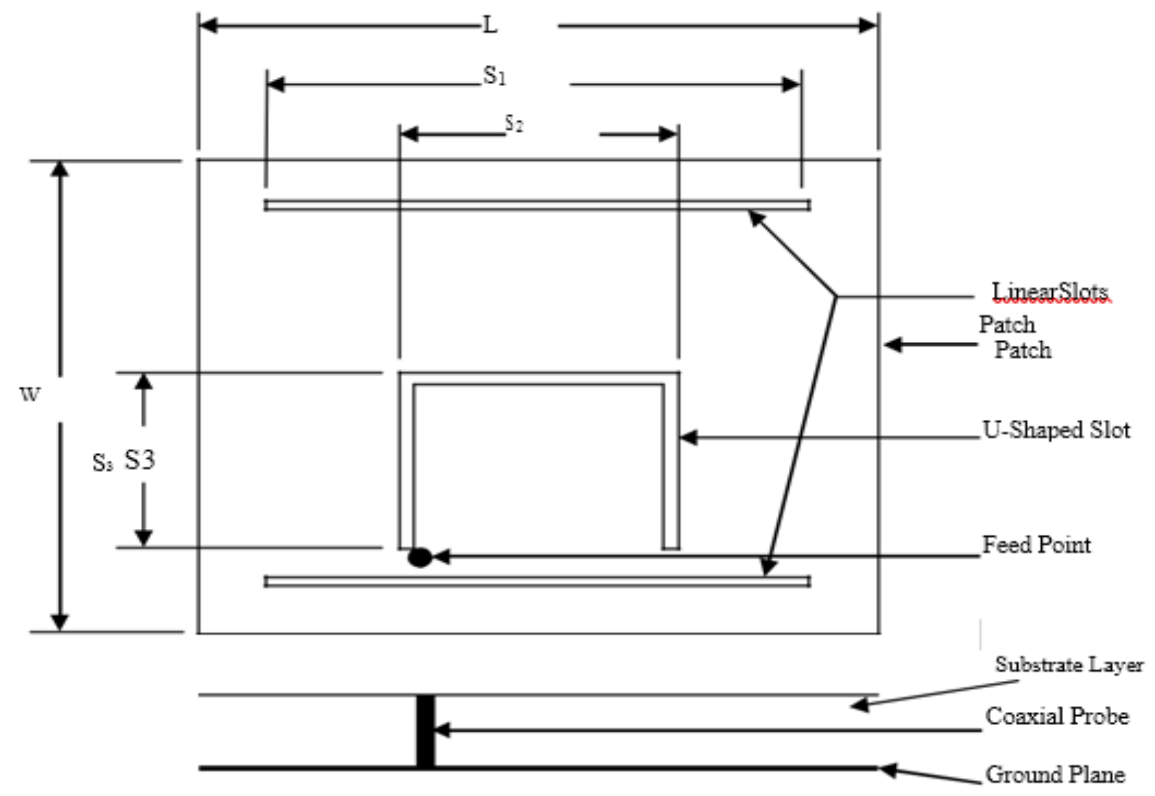

Figure 1 Design of Proposed Antenna 


\section{Determination of Feed Point Location}

In the proposed design, a coaxial probe-type feed is used. The patch's feed point location is changed so that the input impedance is $\mathbf{5 0}$ Ohm. The return loss values for various frequencies and feed location values that change along the $\mathrm{Y}$-axis before changing along the $\mathrm{X}$-axis are shown in Table 1. After analyzing the simulated results, the feed location $(13,9)$ was determined to be the optimal feed point location because the return loss of $-21.35 \mathrm{~dB}$ was obtained corresponding to the centre frequency of $8.10 \mathrm{GHz}$.

Table 1 Return loss between frequency v/s feed position

\begin{tabular}{|l|l|l|l|l|}
\hline \multicolumn{1}{|r|}{ Freq. } & & & & \\
Feed & & & & \\
Position & 5.82 & 6.86 & 7.85 & 8.10 \\
\hline$(24,17)$ & & & & \\
\hline$(24,12)$ & -3.68 & -0.75 & -0.85 & -0.95 \\
\hline$(24,9)$ & -4.16 & -1.26 & -2.0 & -1.36 \\
\hline$(19,9)$ & -4.45 & -2.54 & -5.86 & -2.48 \\
\hline$(\mathbf{1 3 , 9 )}$ & -14.55 & -3.67 & -2.32 & -1.62 \\
\hline$(11,15)$ & $-\mathbf{1 4 . 0 2}$ & $\mathbf{- 1 0 . 9 1}$ & $\mathbf{- 1 0 . 6 8}$ & $\mathbf{- 2 1 . 3 5}$ \\
\hline$(11,12)$ & -3.40 & -2.76 & -3.92 & -1.85 \\
\hline
\end{tabular}

\section{Simulated Parameters of the proposed} antenna

For the proposed antenna's performance, antenna parameters such as return loss, VSWR, and antenna efficiency must be monitored. The characteristic plots produced by the simulation of the proposed multiband antenna are examined in greater depth further below.

\section{Characteristics of Return Loss}

The most important parameter to consider when analyzing any antenna is the return loss. Figure 2 depicts the return loss plot for the proposed antenna at the desired operating frequencies. As shown in Figure 2, the antenna's return losses were $-14.02 \mathrm{~dB}$, $10.92 \mathrm{~dB},-10.68 \mathrm{~dB}$, and $-21.35 \mathrm{~dB}$ for the 
four different bands. According to this graph, the bandwidth values for this antenna where the return loss valueis less than -10 $\mathrm{dB}$ are $150 \mathrm{MHz}, 106 \mathrm{MHz}, 37 \mathrm{MHz}$, and
$151 \mathrm{MHz}$, with respective centre frequencies of $5.82 \mathrm{GHz}, 6.86 \mathrm{GHz}, 7.85 \mathrm{GHz}$, and 8.10 $\mathrm{GHz}$.

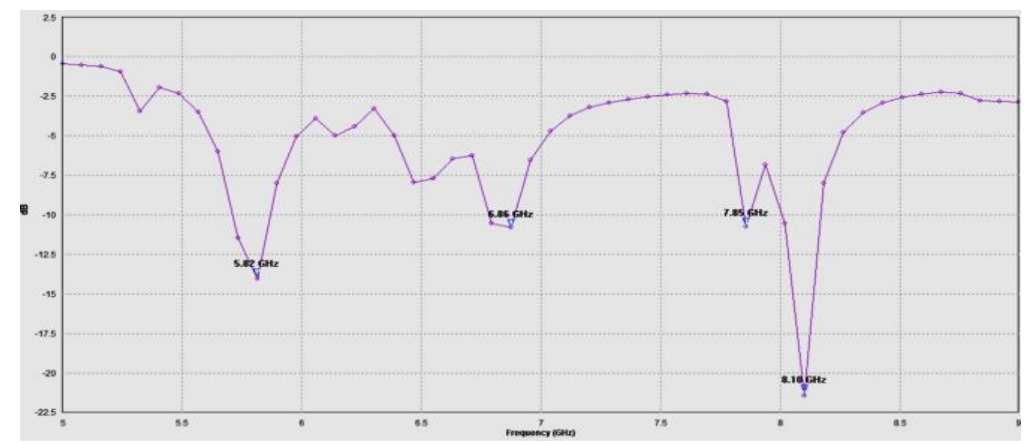

Figure 2 Return Loss v/s frequency of the proposed antenna

\section{VSWR Characteristics}

Figures 3 demonstrate the proposed multiband antenna's voltage standing wave ratio (VSWR) v/s frequency characteristics. For each operating frequency, the VSWR is found to be less than 2.0. The antenna's VSWR was measured to be $1.51,1.81,1.86$, and 1.22 at $5.82 \mathrm{GHz}, 6.86 \mathrm{GHz}, 7.85 \mathrm{GHz}$, and $8.10 \mathrm{GHz}$ frequencies.

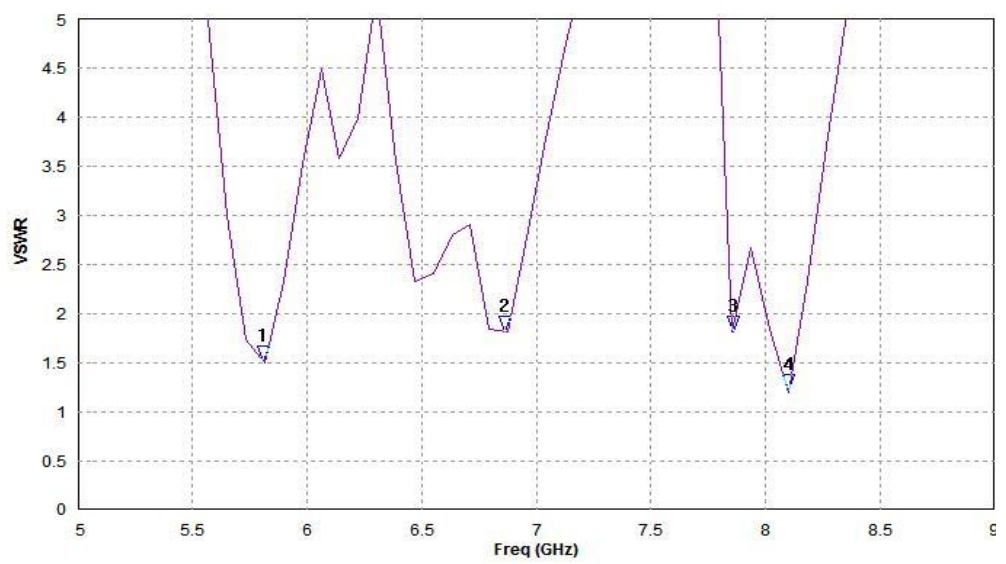

Figure 3 VSWR v/s frequency of the proposed antenna 


\section{Antenna Efficiency and Gain Characteristics}

Figure 4 is depicting the maximum field gain of this antenna for higher frequency band operation, which is estimated to be around $6 \mathrm{dBi}$ for this proposed antenna.
Figure 5 depicts the efficiency graph of the proposed antenna. For the $5.82 \mathrm{GHz}$, $6.86 \mathrm{GHz}, 7.85 \mathrm{GHz}$, and $8.10 \mathrm{GHz}$ frequency bands, the suggested antenna has the efficiency of $70 \%, 56 \%, 46 \%$, and $55 \%$ respectively.

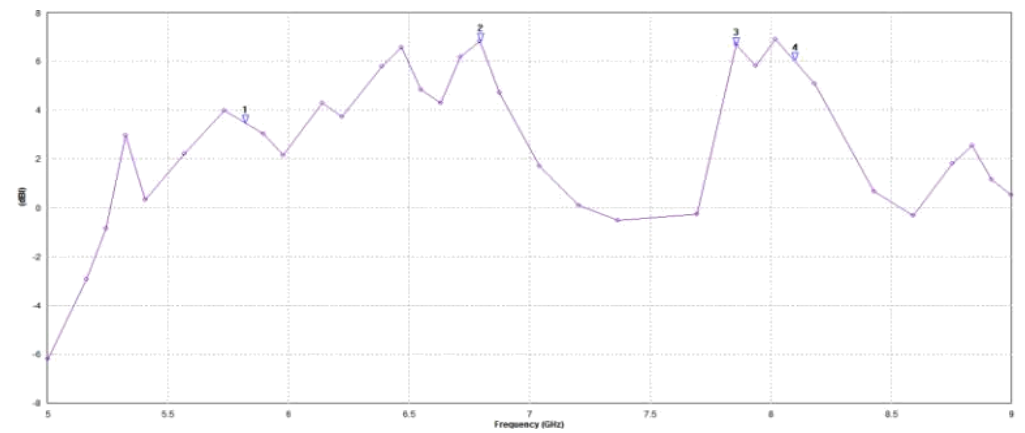

Figure 4 Total field gain v/s frequency of the proposed antenna

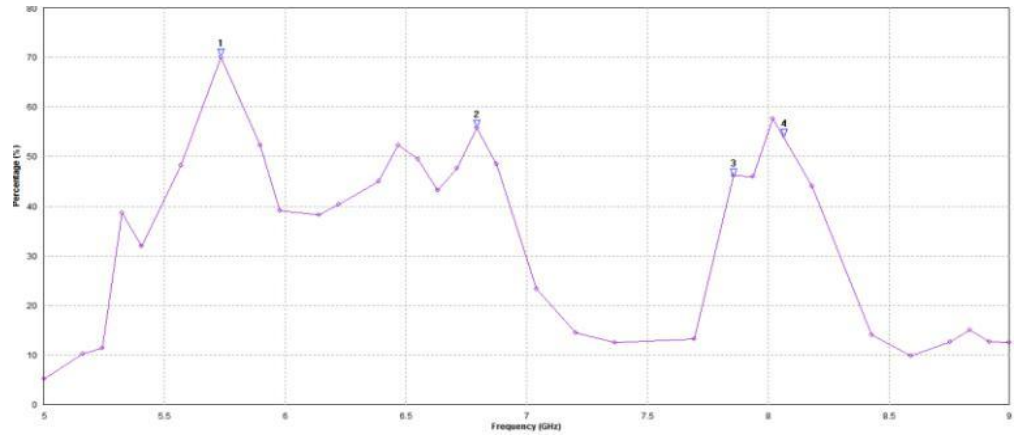

Figure 5 Efficiency v/s frequency of the proposed antenna

\section{Radiation Pattern}

Figures 6 to 9 depict the proposed antenna's radiation pattern for each operating frequency. The antenna's radiation pattern has been optimized to a larger extent.

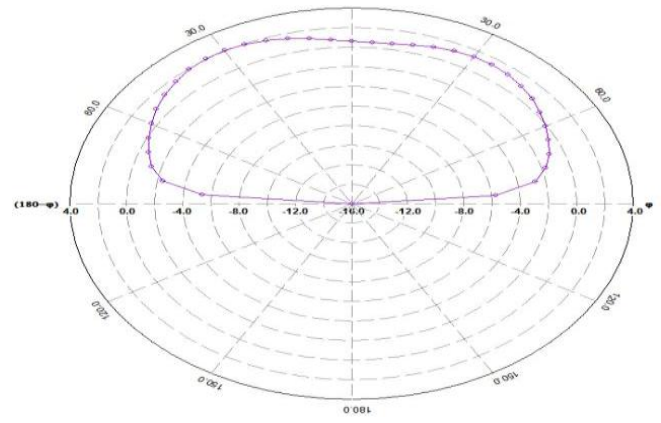

Figure 6 Radiation Pattern of the proposed antenna at 5.82 GHz 


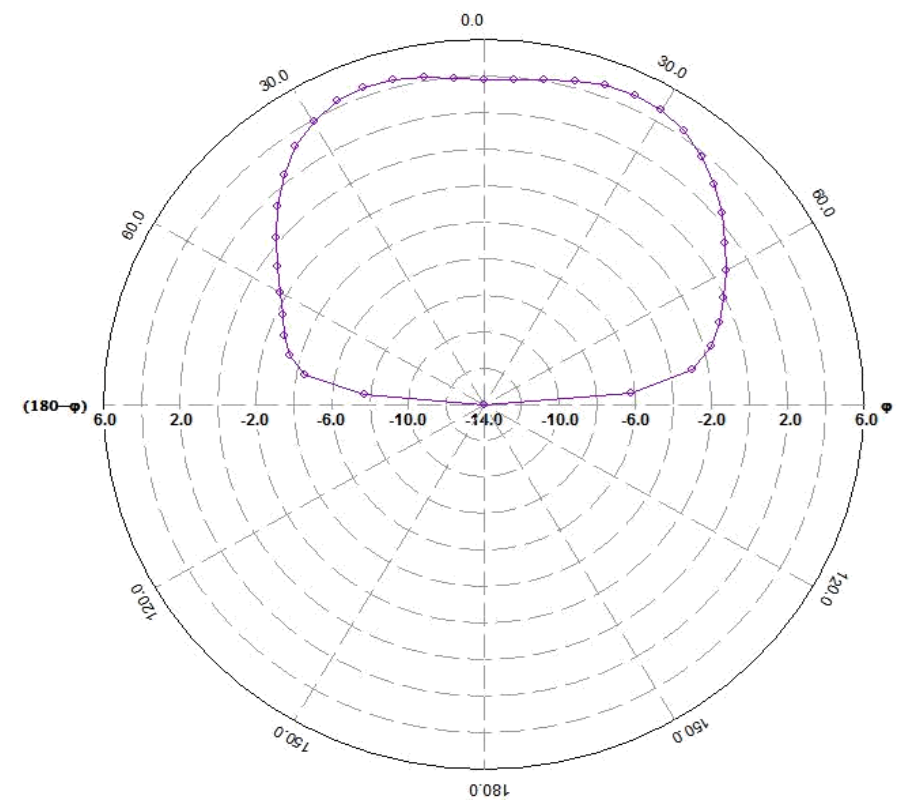

Figure 7 Radiation Pattern of the proposed antenna at $6.86 \mathrm{GHz}$

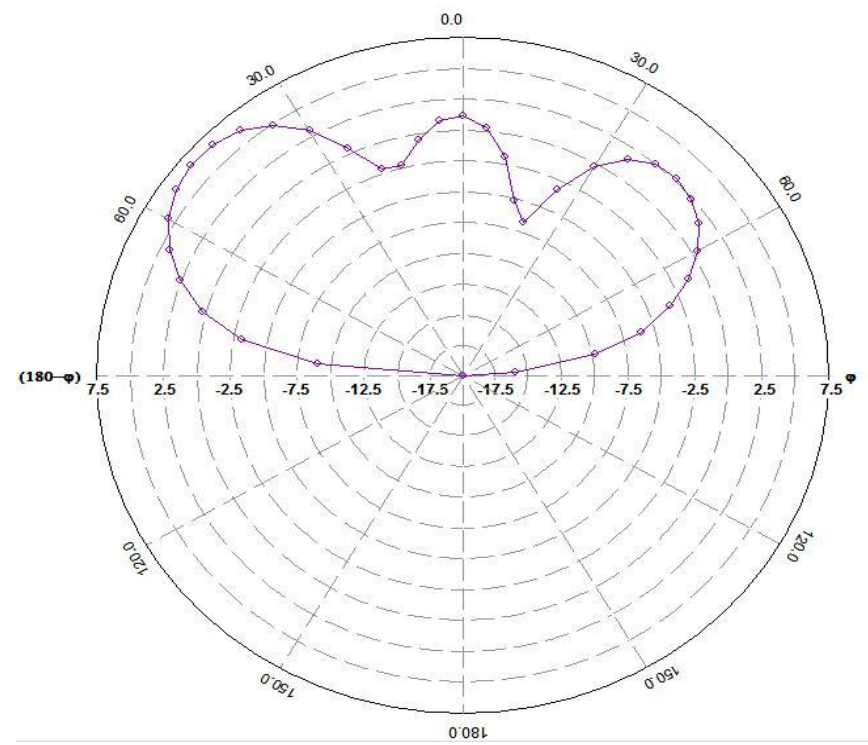

Figure 8 Radiation Pattern of the proposed antenna at $7.85 \mathrm{GHz}$ 


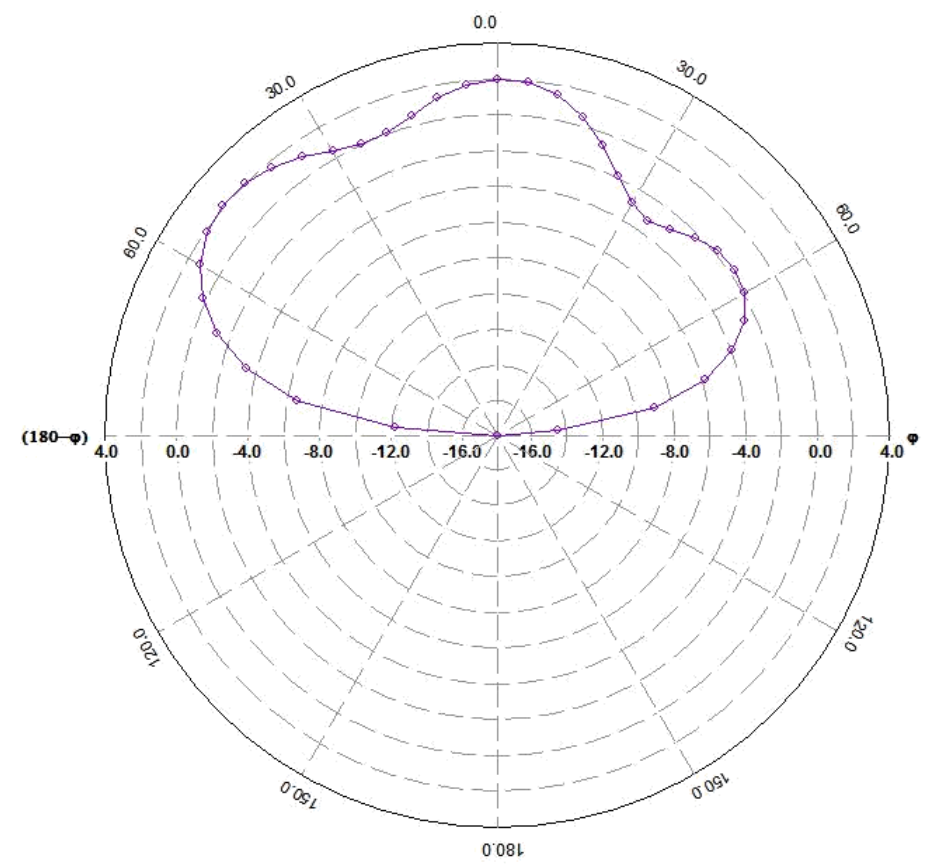

Figure 9 Radiation Pattern of the proposed antenna at $8.10 \mathrm{GHz}$

\section{Directivity}

The antenna's directivity is a fundamental metric that indicates how much power the antenna concentrates in a specific direction. graph that indicates the amplitude of the power in $\mathrm{dB}$ in a specific direction for various operating frequencies of our suggested antenna.

Figure 10 illustrates directivity vs. frequency

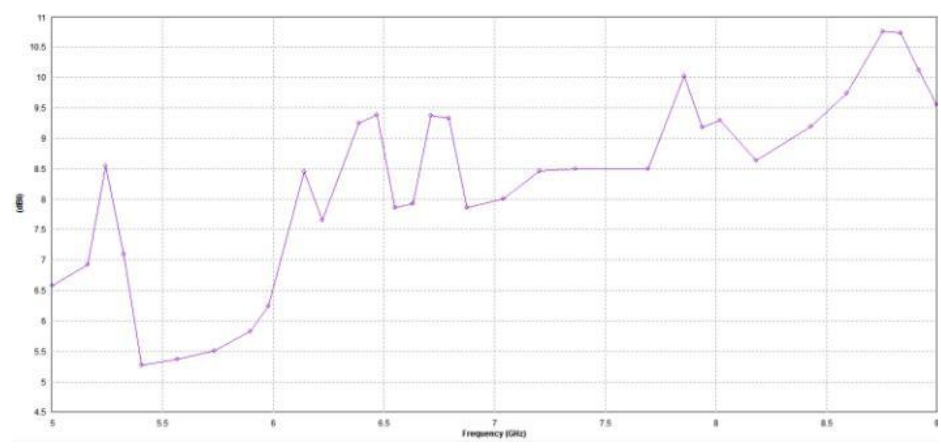

\section{Figure 10 Directivity v/s Frequency Plot for the proposed antenna}

IE3D software was used to build and model

Results and Discussion the multi-band microstrip antenna (IE3D 14, Zeland software Inc.). The transmission line 
model was used to determine the basic design of the antenna. This antenna has been used to simulate the operation of a four-band microstrip antenna. VSWR and return loss statistics were used to evaluate the performance of the proposed antenna. The proposed antenna's maximum bandwidth is determined to be $151 \mathrm{MHz}$. The proposed antenna has a maximum overall field gain of around $6 \mathrm{dBi}$. The maximum efficiency for the $5.82 \mathrm{GHz}$ band is around $70 \%$, and the antenna radiation pattern is also improved.

\section{Conclusion}

A multi-band microstrip antenna was successfully constructed and simulated in this paper. The four-band microstrip antenna was simulated, and the bands were expanded by increasing the dielectric substrate width. This research introduces a unique quad broadband antenna that can operate at four separate frequencies. At four distinct operating frequencies, $150 \mathrm{MHz}, 106 \mathrm{MHz}$, $37 \mathrm{MHz}$, and $151 \mathrm{MHz}$ of bandwidth were attained, with centre frequencies of 5.82 $\mathrm{GHz}, 6.86 \mathrm{GHz}, 7.85 \mathrm{GHz}$, and $8.10 \mathrm{GHz}$, respectively. In the range of frequencies from $5 \mathrm{GHz}$ to $9 \mathrm{GHz}$, the suggested antenna can be employed for wireless and mobile applications under IEEE 802.11 $\mathrm{a} / \mathrm{b} / \mathrm{g}$ standard. The proposed antenna can be used for satellite as well as wireless communication systems like modern mobile handsets and laptops for WLAN applications. In the future, this proposed antenna for a variety of wireless communication devices and systems might be simply manufactured on a single-layer, relatively thin substrate. Different outcomes can be produced by altering the dimensions of the main patch, slots, and U slot.

\section{References}

Ahsan M. R., Islam M. T. and Ullah M. H. (2016). Design and performance analysis of small-sized multiband microstrip patch antenna on custom-made biopolymer substrate. Science and Engineering of Composite Materials: 23(6), 729-735, doi: 10.1515/secm-2014-0409

Amal K. A., Joseph S., Kumariamma S., Mondal A. K. and Ratheesh R. (2016). Compact multiband microstrip patch antenna for wireless applications. International Conference on Communication Systems and Networks (ComNet): 153-156, doi: 10.1109/CSN.2016.7824005

Bhattacharyya A.K., and Garg R.(1985). Generalized transmission line model for microstrip patches. IEEE Proceedings: 132, 93-98

Cao Y.-F., Cheung S.W. and Yuk T.-I. (2015). A multiband slot antenna for GPS/WiMAX/WLAN systems. IEEE Trans. Antennas Propagation : 63, 952-958, doi:10.1109/TAP.2015.2389219

Chourasia S. and Jain P. K. (2020). Multiband microstrip Patch Antenna with Closed Cshape Conducting Strip. International 
Conference on Computer Communication and Informatics (ICCCI): 1-3, doi: 10.1109/ICCCI48352.2020.9104128

Garg, R, Bhartia, P, Bahl, I and Ittipiboon, A. (2001). Microstrip antenna design handbook, Artech House, Boston.London

Hasan C. Z., Khan A. A., Fahim-Al-Fattah M., Amin M. A. and Mohammad S. (2017). A novel quad-band microstrip patch antenna for WLAN, WiFi, WiMAX applications. IEEE 9th International Conference on Communication Software and Networks (ICCSN): 718-721, doi: 10.1109/ICCSN.2017.8230205.

IE3D 14, Zeland software Inc.

Jabar A. A. S. A. and Naji D.K. (2019). Design of Miniaturized Quad-Band Dual-Arm Spiral Patch Antenna for RFID, WLAN and WiMAX Applications. Progress In Electromagnetics Research C: 91, 97-113, doi:10.2528/PIERC19011706

Kumar, G and Ray, KP (2003). Broadband microstrip Antenna, Artech House, Boston.London

Kumar K. and Gangwar R.P.S. (2016). Design of Six Band Microstrip Antenna. International Journal of Latest Technology in Engineering, Management \& Applied Science-IJLTEMAS: 5(3), 52-55

Liu H.-W., Wen P., Zhu S.-S., Ren B.-P., Guan X.-H. and Yu H. (2015). Quad-band CPWfed monopole antenna based on flexible pentangle-loop radiator. IEEE Antennas Wireless Propag. Lett., 14, 1373-1376. doi: 10.1109/LAWP.2015.2406391

Nataraj C., Ismael A. A., Selvaperumal S. and Khan S. (2017). Compact multiband microstrip patch antenna with slot-rings for wireless applications. IEEE 15th Student Conference on Research and Development (SCOReD): $\quad 428-433, \quad$ doi: 10.1109/SCORED.2017.8305351
Prasad L., Ramesh B., Kumar K. S. R. \& Vinay K. P. (2018). Design and Implementation of

Multiband Microstrip Patch Antenna for Wireless Applications. Advanced Electromagnetics, 7(3), 104-107. doi: 10.7716/aem.v7i3.646

Rhazi Y., Bakkali O.El., Bri S., Lafkih M.A., Mrabet Y. El., Nejdi I.H. and Srifi M.N. (2018). Design and Analysis of a Novel Multiband Microstrip Patch Antenna for Wireless Communication, International Symposium on Advanced Electrical and Communication Technologies (ISAECT): 1-5, doi: 10.1109/ISAECT.2018.8618828

Rhazi Y., Bakkali O. El, Merabet Y. El, Lafkih M.A., Bri S. and Srifi M.N.(2019). Novel Design of Multiband Microstrip Patch Antenna for Wireless Communication. Advances in Science, Technology and Engineering Systems Journal: 4(3), 63-68, doi: 10.25046/aj040310

Sunthari P.M. and Veeramani R. (2017). Multiband microstrip patch antenna for $5 \mathrm{G}$ wireless applications using MIMO techniques. First International Conference on Recent Advances in Aerospace Engineering (ICRAAE): 1-5, doi: 10.1109/ICRAAE.2017.8297241

Wang R., Zhang L.J., and Hu S.W. (2018). A novel ACPW-fed quad-band hybrid antenna for wireless applications. International Journal of Microwave and Wireless Technologies, 10(4), 460-468, doi:10.1017/S175907871700143X 